\title{
Investigation on blasted tool surfaces as a measure for material flow control in sheet-bulk metal forming
}

\author{
Marion Merklein, Maria Löffler, Daniel Gröbel, and Johannes Henneberg* \\ Institute of Manufacturing Technology, Friedrich-Alexander-Universität Erlangen-Nürnberg (FAU), 91058 Erlangen, Germany
}

Received: 18 January 2019 / Accepted: 3 May 2019

\begin{abstract}
Highly integrated and closely tolerated functional components can be produced by sheet-bulk metal forming which is the application of bulk forming operations on sheet metal. These processes are characterized by a successive and/or simultaneous occurrence of different load conditions which reduce the geometrical accuracy of the parts. One challenge within sheet-bulk metal forming is the identification of methods to control the material flow to improve the product quality. A suitable approach is the local modification of the tribological conditions. Within this study, requirements regarding the needed adaption of the tribological system for a specific process were defined by numerical investigations. The results reveal that a local increase of the friction leads to an improved geometrical accuracy. Based on these results, abrasive blasting as a method to modify the tool surface and thus influencing the tribological behaviour was investigated. For the determination of the tribological mechanism of blasted tool surfaces, the influence of different blasting media as well as blasting pressures on the surface integrity and the friction were determined. Additionally, the functional stability of a modification was investigated. Finally, the correlations between surface properties and friction conditions were used to derive the mechanisms of blasted tool surfaces.
\end{abstract}

Keywords: Tribology / cold forming / surface modification

\section{Introduction}

Nowadays, the manufacturing industry is enforced to upgrade their products due to rising customer and legal requirements. Lightweight construction and minimization of material usage is a promising approach to deal with these new requirements. Weight reduction is achievable by the usage of highly integrated and closely tolerated parts. Due to rising economic competition, parts must be produced by time and cost efficient manufacturing processes. Metal forming is suitable to fulfil these economic requirements, because it enables an efficient production due to high material usage and low production time per part [1]. Conventional sheet and bulk forming operations are limited while producing highly integrated and closely tolerated parts. The existing limitations motivate the development of the new process class sheet-bulk metal forming (SBMF). SBMF processes are defined as the application of bulk forming operations on sheet metal [2]. By this process, class sheet metal parts with integrated functional elements can be produced in an efficient way. In SBMF processes high tribological loads

\footnotetext{
* e-mail: johannes.henneberg@fau.de
}

which are characteristic for bulk forming operations occur simultaneously and/or successive with lower tribological loads like in sheet metal forming processes. As a result, the plastic material flow is negatively influenced into areas with lower tribological loads. Hence, the part quality in terms of geometrical accuracy is insufficient. As shown in Figure 1, the die filling of the functional elements is incomplete. Consequently, the in service behaviour of the produced parts is impaired. Stress concentrations due to sharp radii and complex geometries of the die are already causing high tool loads [3]. Thus, the enhancement of the die filling by higher forming forces is limited by these. Hence, other ways to control the material flow during forming need to be developed. The local adaption of the friction to control the material flow seems to be a promising approach [4]. On tool side, the occurring friction can be influenced by the material and the surface properties [5].

Locally modified surfaces, also named tailored surfaces, which adapt the friction have the potential to improve the part quality by increasing the die filling of functional elements [4]. The material flow is led into the cavities by a local reduction of friction and/or an inhibition of the material flow in other areas of the part by a local increase of friction. Numerical investigations can be utilized to analyse the requirements for tailored surfaces by examining the 


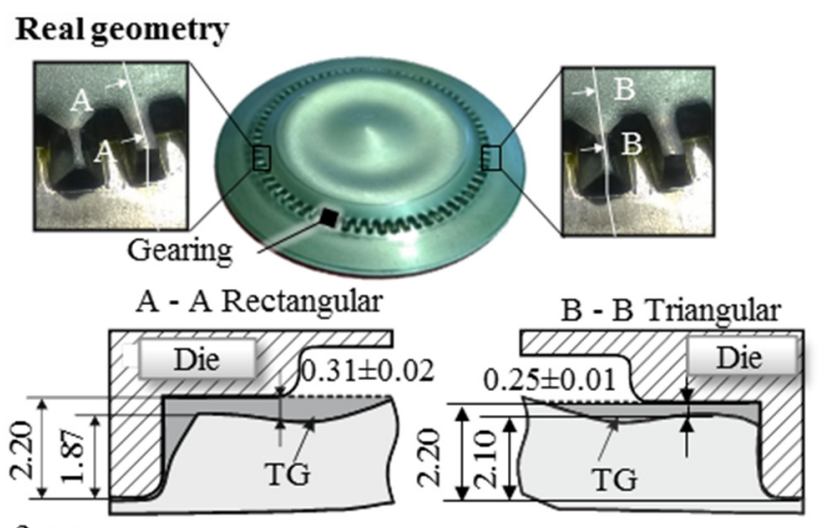

$2 \mathrm{~mm}$

\section{Die filling}

Material $\quad 1.0338$ Press stroke $1.7 \mathrm{~mm}$

Initial diameter $120 \mathrm{~mm} \mathrm{n} 3$

Real geometry $\quad \square$ Target geometry TG

Fig. 1. Die filling.

tribological loads during SBMF. In addition, the influence of locally varying friction on the forming process can be evaluated by numerical investigations.

The adjustment of tool- and workpiece-surfaces is one possibility to locally influence the friction. Workpiece-sided modifications are disadvantageous because every workpiece has to be adapted. Hence, the SBMF-process chain is extended and economic competitiveness may decline. By contrast, tool-sided surface modifications do not lengthen the process chain. In this research, the requirements for tool-sided tailored surfaces in a specific SBMF process are analysed by numerical investigations and the influence of tool-sided abrasive blasting as a method to influence the surfaces integrity and friction is analysed in a laboratory test. The aim of these investigations is to identify fundamentally functional relations between the tool surfaces integrity and the friction.

\section{Methodology and experimental setup}

This study focuses the evaluation of the potential of tailored surfaces used to improve a specific SBMF process. General requirements for tailored surfaces should be derived. In cold forging, numerical simulations are used to analyse the material flow, the die filling and the tribological loads [6]. Hence, as shown in Figure 2, numerical investigations are applied to investigate the tribological loads of a specific SBMF process. Based on these results, a numerical model with modified friction is designed. The potential of locally adapted friction for controlling the material flow and increasing geometrical accuracy of parts is investigated. The generated knowledge is used to derive requirements for tailored surfaces. Subsequently, the potential of abrasive blasting of tools to tailor the surfaces is evaluated in a laboratory test.

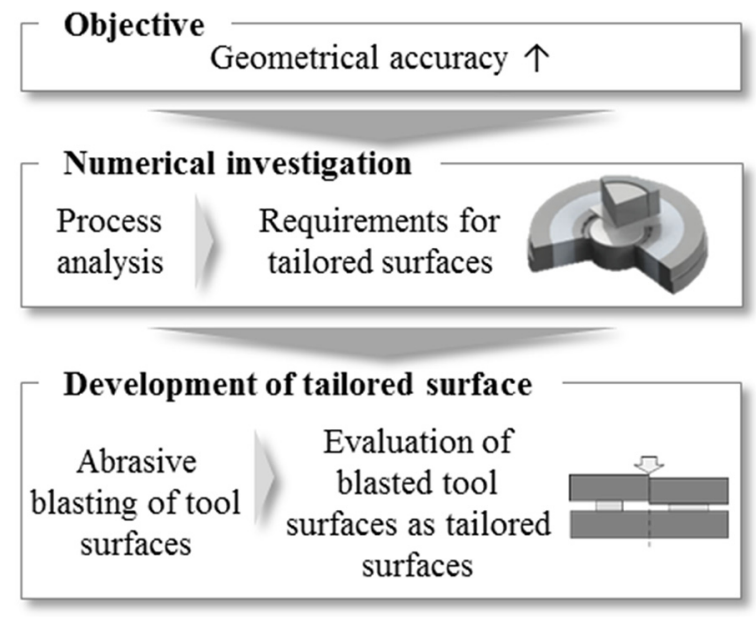

Fig. 2. Methodology.

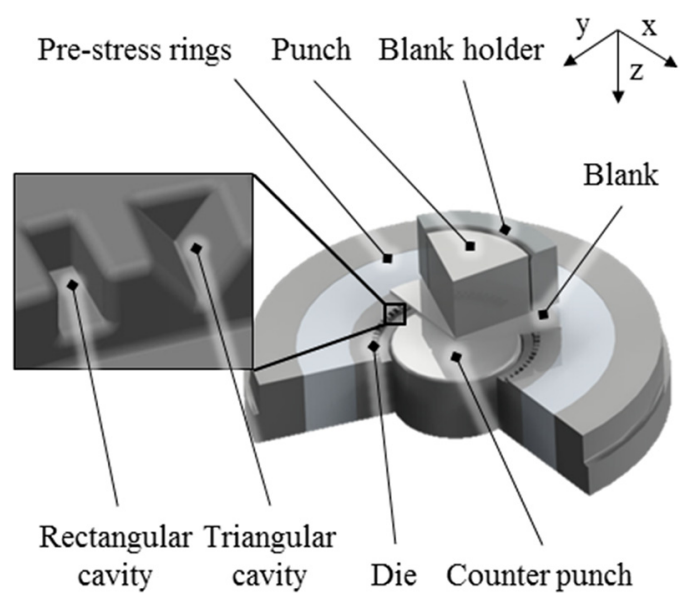

Fig. 3. Tool setup of the forward extrusion process [5].

Functional relations between tool surface integrity and friction are fundamentally analysed. Conclusively, the functional stability of one blasted surface is analysed.

As an example for SBMF a full forward extrusion process, which produces parts with rectangular and triangular functional elements, is numerically examined. The process is illustrated in Figure 3.

The blank which is made out of the deep drawing steel 1.0338 with a diameter of $120 \mathrm{~mm}$ and a thickness of $2 \mathrm{~mm}$ is formed by a punch with a stroke of $1.7 \mathrm{~mm}$ [7]. During the forming process, the blank is supported by a counter punch with a force of $40 \mathrm{kN}$ to reduce the material flow in the inner area of the part. In addition, it is supported by a blank holder with a force of $360 \mathrm{kN}$. To reduce the simulation time, a $10^{\circ}$-segment of the part was processed. The validation of the model was published in [7].

For the design of tailored surfaces, the tribological loads, more specifically the contact normal stresses, the sliding paths and the surface enlargements, of the SBMF process were analysed. A model with locally adapted tribological conditions was simulated for different friction 


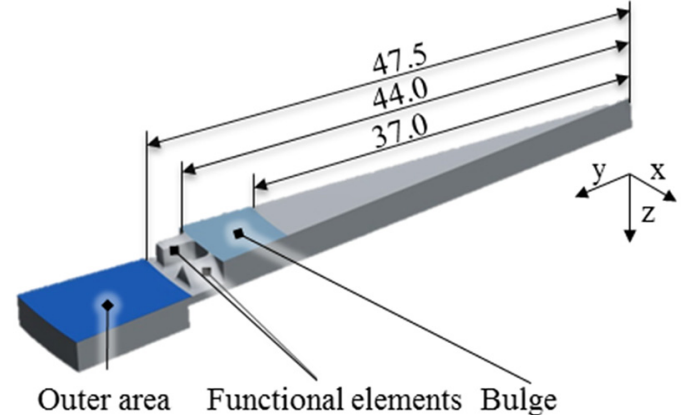

Fig. 4. Investigated areas for the material flow analysis.

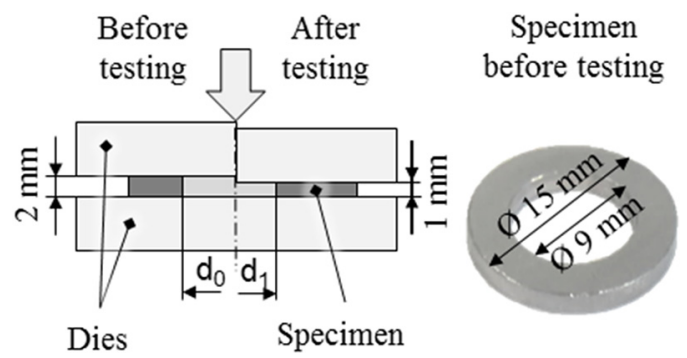

Fig. 5. Setup of the ring compression test.

factors. For the evaluation of the effectiveness of a local adaption, the results were compared with simulations with globally homogeneous friction. The material flow in the cavities of the functional elements was analysed by calculating the ratio between the volume of the formed functional element and the volume of the die cavities. In addition, the volumes of the outer area and the bulge as shown in Figure 4 were compared to the volume of these areas before forming. Based on the material flow analysis, requirements for tailored surfaces were derived.

Abrasive blasting was chosen as a method to modify the tool surfaces. The potential of abrasive blasting to fulfil the requirements for tool-sided tailored surfaces and the influence on the friction was investigated. Six differently blasted surfaces were analysed in the ring compression test (RCT). In the RCT, a ring made out of 1.0338 is compressed from $2 \mathrm{~mm}$ to $1 \mathrm{~mm}$ height as shown in Figure 5.

The inner diameter after forming is sensitive to the friction [8]. In case of high friction, a smaller inner diameter occurs. The geometry of the specimen before forming was selected based on a numerical study guaranteeing a high sensitivity for the specific forming conditions of SBMF processes [9]. An outer diameter of $15 \mathrm{~mm}$ and an inner diameter of $9 \mathrm{~mm}$ were selected. The friction factor $m$ is calculated based on equation (1), which was fitted for the selected specimen geometry and material in [4].

$$
m=\left(-0.07722 * d_{1}+0.9696\right) /\left(d_{1}-5.834\right) \text {. }
$$

The influence of the lubricant Beruforge $150 \mathrm{DL}$ on the RCT was investigated in preliminary tests. An amount of $10 \mathrm{~g} / \mathrm{m}^{2}$ was chosen, since saturation is reached for this amount of lubricant. For the RCTs, five specimens were formed per tool surface to guarantee statistic relevance. The

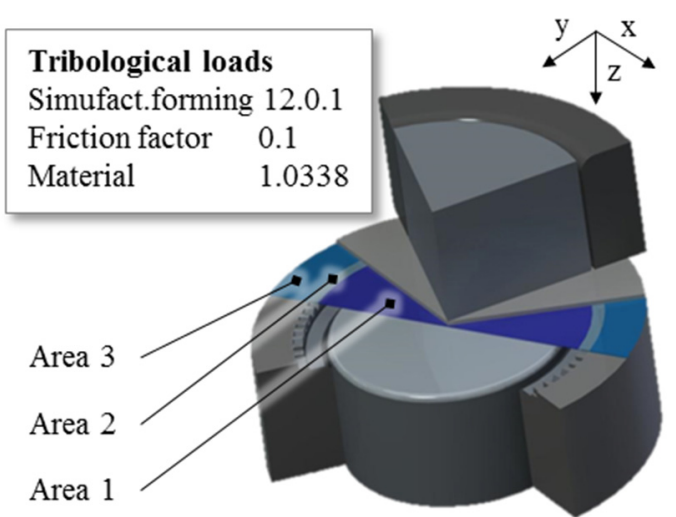

Fig. 6. Areas with different tribological loads.

RCT was conducted on the hydraulic deep-drawing press Lasco 100SO with a forming velocity of the upper die of $10 \mathrm{~mm} / \mathrm{s}$. The forming tools are made out of powder metallurgical tool steel 1.3344 with a hardness of $61 \pm 2$ HRC. The tool surfaces were ground before blasting. For the blasting process, two different blasting media and three different blasting pressures were used with the Peenmatic 620S. The topography of the tools were analysed by confocal microscopy with a Keyence VKX200. To characterize the tool surfaces, the reduced peak height $R_{p k}$ as a parameter describing the average height of the roughness peaks which are higher as the core roughness are analysed [10]. This parameter was chosen because it describes the tendency for mechanical interlocking of roughness peaks and measured tactile with a MarSurf GD120 in accordance to DIN EN ISO 4287. The influence of the abrasive blasted surfaces on the friction is analysed by comparing the resulting friction factors. The relation between tool topography and friction enables the evaluation of abrasive blasting for tailored surfaces. The investigation of tool surfaces after the forming of $100 \mathrm{RCT}$-specimens enables the estimation of the wear resistance of blasted tool surfaces. Based on the result, the potential of abrasive blasted tool surfaces for processes of SBMF is rated.

\section{Numerical investigations}

The tribological loads influence the material flow of forming processes [11]. Hence, they have to be investigated for the design of tailored surfaces. The occurring contact normal pressure, the sliding path and the surface enlargement are analysed for a friction factor of 0.1 . Three areas with different loads are identified and presented in Figure 6 and Table 1.

The maximum tribological loads in area 1 as well as in area 3 are low, due to the great contact area between tool and workpiece and thus lower resulting strains. In addition, the surface enlargements and the sliding paths are low. In both areas, maximum contact normal pressures between 183 and $282 \mathrm{MPa}$ occur. These low contact normal pressures are characteristic for sheet metal forming processes [12]. The forming of functional elements causes high contact normal pressures up to $2803 \mathrm{MPa}$ as they occur in bulk metal forming operations. As a result of the long sliding paths and high 
Table 1. Maximum tribological loads of the SBMF process.

\begin{tabular}{llll}
\hline Maximum values & Area 1 & Area 2 & Area 3 \\
\hline Contact normal pressure in & 282 & 2803 & 183 \\
MPa & & & \\
Surface enlargement in $\%$ & 0.00 & 70.00 & 5.38 \\
Sliding path in mm & -0.61 & 2.09 & 1.60 \\
\hline
\end{tabular}

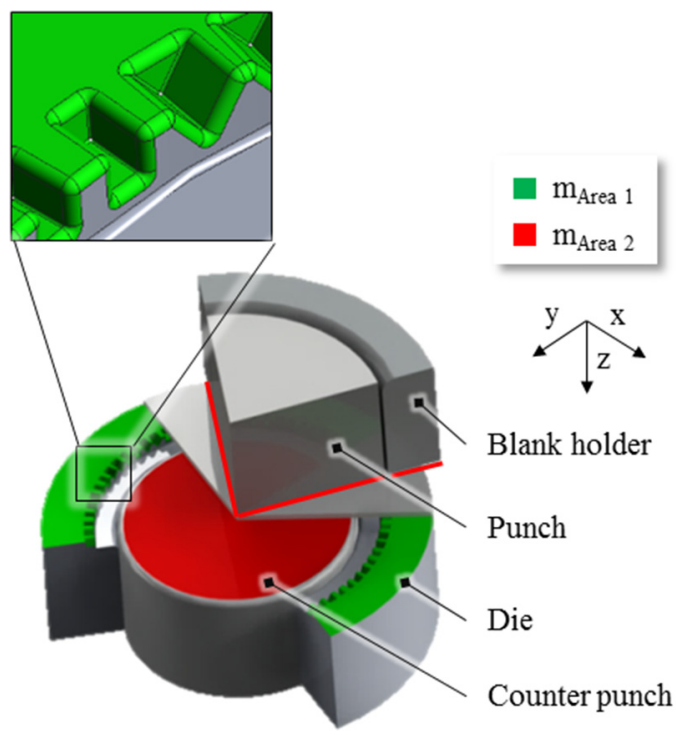

Fig 7. Areas with locally adapted friction factors.

surface enlargements, the risk of a disconnection of the lubrication film rises. A disconnected lubrication film would increase the tribological loads even further.

The varying tribological loads influence the material flow. The material flow is directed into areas with low tribological loads. Thus, the rectangular functional elements reach a die filling of only $83.63 \%$ because the material flows into the areas 1 and 3 next to the functional element. Hence, the volume of the workpiece in the bulge and outer area rises up to 106.36 and $106.04 \%$ compared to the volume before the forming. To reduce the material flow in these areas and consequently increase the volume of the functional elements the friction has to be adapted. The influence of adapted friction is examined with two simulation models illustrated in Figure 7 and Table 2.

By means of a local increase of friction in all areas except for the die, the material flow into the functional elements should be supported. For the examination of the potential of a material flow control by tailored surfaces, the friction factor of all tool surfaces except of the die are increased from 0.1 up to 0.6 in six steps (locally adapted model 1, No. 1 to 6 ).

There is no knowledge about the maximum friction factor after blasting of tool surfaces. For the numerical investigations, 0.6 is chosen as highest friction factor. The simulations with locally adapted friction are evaluated by a comparison to simulations with globally homogeneous friction factors between 0.1 and 0.6 (global model 2, No. 7
Table 2. Experimental design of the numerical material flow study.

\begin{tabular}{llllll}
\hline & \multicolumn{2}{c}{ Locally adapted model 1} & & \multicolumn{2}{c}{ Global model 2 } \\
\cline { 1 - 2 } No. & $m_{\text {area1 }}$ & $m_{\text {area2 }}$ & & No. & $m_{\text {global }}$ \\
\hline 1 & 0.1 & 0.1 & & \\
2 & 0.1 & 0.2 & & 7 & 0.2 \\
3 & 0.1 & 0.3 & & 0.3 \\
4 & 0.1 & 0.4 & & 9 & 0.4 \\
5 & 0.1 & 0.5 & & 10 & 0.5 \\
6 & 0.1 & 0.6 & & 11 & 0.6 \\
\hline
\end{tabular}

to 11). The friction factor 0.1 is chosen as the lowest friction factor, since lapped tool surfaces cause approximately this friction factor in the RCT.

The areas which are examined for the material flow analyses are defined in Figure 4. These areas are analysed since they are critical in terms of geometrical accuracy. The local increase of the friction in model 1 reduces the volume of the outer area from $106.36 \%$ at a friction factor of 0.1 to $104.18 \%$ at a friction factor of 0.6 as illustrated in Figure 8. Hence, the die filling of the rectangular functional element increases consistently from $83.63 \%$ up to $92.39 \%$. Since the die filling of the triangular functional element is already $97.93 \%$ at a low friction factor and variation of the friction only causes minor changes of the die filling up to $98.32 \%$, further investigations are focused on the rectangular element. The volume of the bulge increases for the locally adapted model from $106.04 \%$ up to $110.34 \%$. In the area of the bulge lower friction occurs, due to the one-sided contact between workpiece and tool in this area. Hence, the volume of the outer area is not only transferred into the functional elements but also into the bulge. A global increase of the friction from 0.1 to 0.6 causes a higher decrease of the volume of the outer area. The volume at a friction factor of 0.6 is $103.51 \%$. The volume is lower compared to the locally adapted model, since the friction of the die is also increased. Hence, the friction force in the outer area increases on both sides of the workpiece. In comparison to the locally adapted model, more material is transferred to other parts of the workpiece. Due to this fact, the die filling of the rectangular functional element and the volume of the bulge is in the global model for all determined simulations slightly higher than in the locally adapted model.

As shown in Figure 9, the friction also influences the required forming forces. Due to a higher friction, the material flow is inhibited. The increase of the friction in both investigated models causes higher forming forces. A global variation of the friction factor from 0.1 to 0.6 increases the necessary forming forces from $1320 \mathrm{kN}$ up to $2317 \mathrm{kN}$. A local adaption of the friction causes lower forming forces. The required forming force in the simulations with locally adapted friction is for all variants about $200 \mathrm{kN}$ lower compared to the variants with globally homogenous friction. Since the maximum forming force is an indicator for the external load of a forming tool [13], a lower forming force due to a local adaption of the friction may reduce the tool load. For instance, a global increase of 

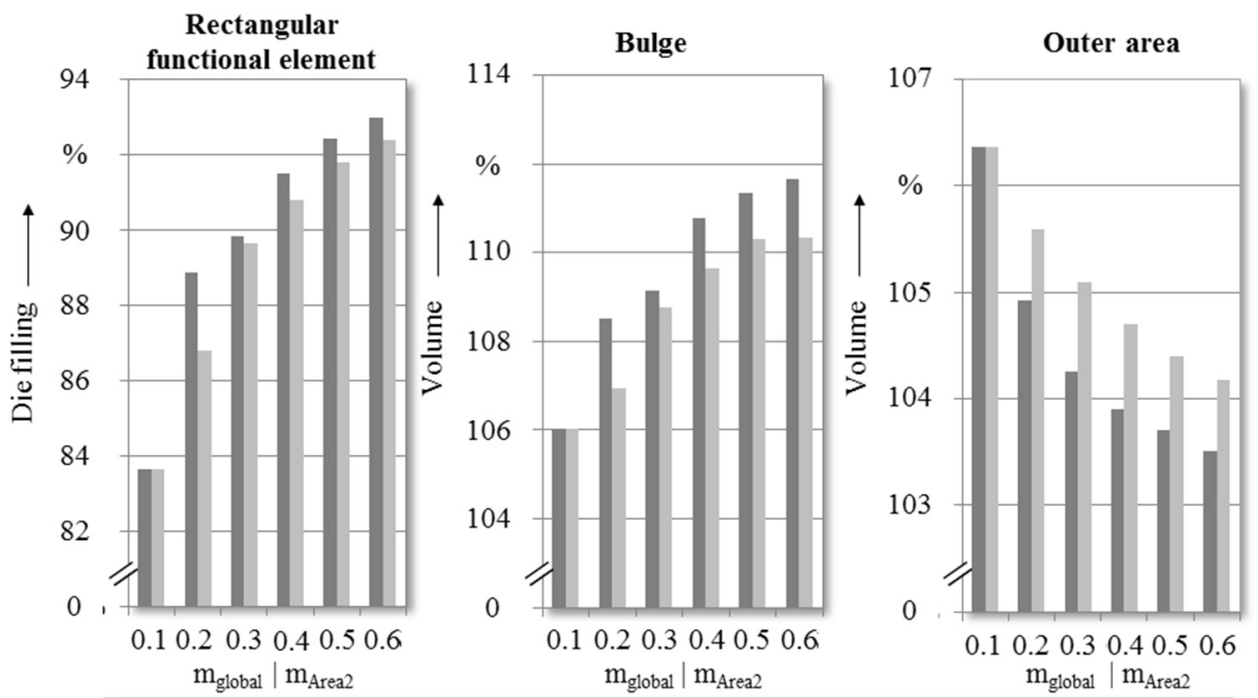

\begin{tabular}{|c|c|}
\hline \multicolumn{2}{|l|}{ Material flow } \\
\hline Simufact.forming & 12.0.1 $\square$ Global model \\
\hline Material & $1.0338 \square$ Locally adapted \\
\hline $\begin{array}{l}\mathrm{t}_{0} \\
\mathrm{~m}_{\text {Area1 }} 0.1\end{array}$ & $2 \mathrm{~mm}$ model \\
\hline
\end{tabular}

Fig. 8. Material flow for the globally and locally adapted models for different friction factors.
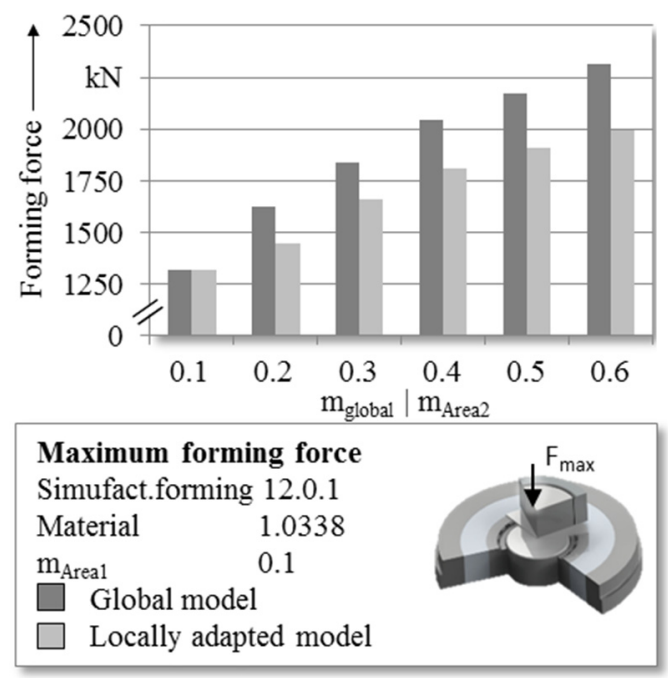

Fig. 9. Influence of friction on maximum forming forces for the globally and locally adapted models.

the friction factor from 0.1 to 0.3 raises the reduced stress in the highest loaded radius of the triangular cavity from $2713 \pm 205 \mathrm{MPa} \quad\left(n_{\text {elements }}=5\right)$ up to $3060 \pm 130 \mathrm{MPa}$, whereas a local adaption of the friction factor only increases the reduced stress to $2744 \pm 66 \mathrm{MPa}$.

The results of the numerical investigations are concluded in Figure 10. The numerical study has shown that an increase in friction results in reduced material flow in the outer area. Hence, the die filling of the rectangular functional elements is improved.

\begin{tabular}{|c|c|c|c|c|c|c|}
\hline \multirow{2}{*}{$\begin{array}{c}\mathrm{m}_{\mathrm{g}} / \mathrm{m}_{2} \uparrow \uparrow \uparrow \\
\mathrm{m}_{1} \rightarrow\end{array}$} & \multicolumn{4}{|c|}{ Material flow } & \multirow{2}{*}{\multicolumn{2}{|c|}{$\begin{array}{l}\text { Forming } \\
\text { force/ } \\
\text { Tool load }\end{array}$}} \\
\hline & \multicolumn{2}{|c|}{$\begin{array}{l}\text { Rectangular } \\
\text { functional } \\
\text { element }\end{array}$} & $\begin{array}{c}\text { Outer } \\
\text { area }\end{array}$ & Bulge & & \\
\hline $\begin{array}{l}\text { Global } \\
\text { model }\end{array}$ & \multicolumn{2}{|l|}{$\uparrow \uparrow \uparrow$} & $\downarrow \downarrow$ & $\uparrow \uparrow$ & \multicolumn{2}{|c|}{$\uparrow \uparrow \uparrow$} \\
\hline $\begin{array}{l}\text { Locally } \\
\text { adapted } \\
\text { model }\end{array}$ & \multicolumn{2}{|l|}{$\uparrow \uparrow$} & & $\uparrow$ & \multicolumn{2}{|r|}{$\uparrow$} \\
\hline \multicolumn{7}{|c|}{ Influence } \\
\hline \multicolumn{3}{|c|}{ Decrease } & \multicolumn{4}{|c|}{ Increase } \\
\hline$\stackrel{\downarrow}{\downarrow}$ & $\begin{array}{c}\downarrow \downarrow \\
\text { Medium }\end{array}$ & $\begin{array}{l}\downarrow \downarrow \downarrow \\
\text { High }\end{array}$ & \multicolumn{2}{|c|}{$\begin{array}{c}\uparrow \\
\text { Low }\end{array}$} & $\begin{array}{c}\uparrow \uparrow \\
\text { Medium }\end{array}$ & $\begin{array}{c}\uparrow \uparrow \uparrow \\
\text { High }\end{array}$ \\
\hline \multicolumn{7}{|c|}{ Evaluation } \\
\hline \multicolumn{2}{|c|}{ Negative } & \multicolumn{3}{|c|}{ Neutral } & \multicolumn{2}{|c|}{ Positive } \\
\hline
\end{tabular}

Fig 10. Influence of adapted tribological systems on SBMF process.

Nevertheless, the volume of the bulge as well as the required forming forces increase in both analysed models. By a local adaption of the friction, the necessary forming forces could be reduced with slightly lower die filling of the rectangular functional element compared to a model with globally homogenous friction. For instance, a local adaption of the friction reduces the necessary forming forces for a friction factor of 0.3 by $9.55 \%$, whereas the die filling of the 
a)

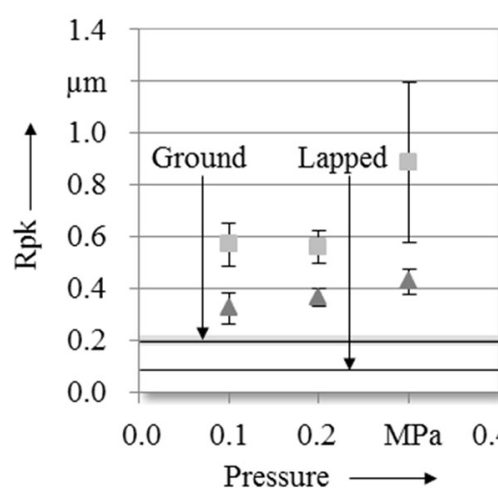

b)
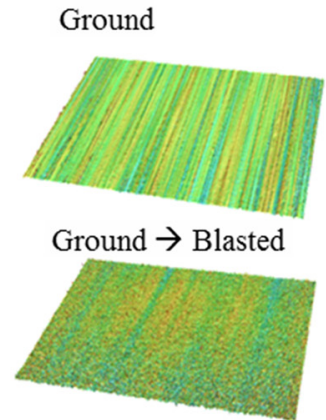

Blasting 15 to $35 \mu \mathrm{m}$

media

Pressure $0.1 \mathrm{MPa}$

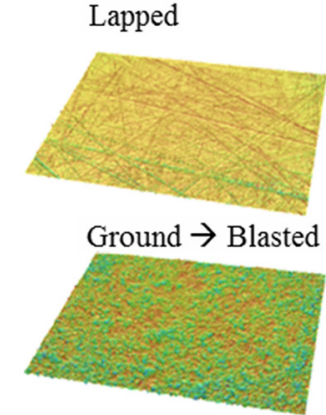

50 to $70 \mu \mathrm{m}$

$0.3 \mathrm{MPa}$

\begin{tabular}{|c|c|c|c|c|c|c|c|c|}
\hline \multicolumn{9}{|c|}{ Topography } \\
\hline \multicolumn{4}{|c|}{ Tactile roughness measurement } & \multicolumn{2}{|c|}{ Optical Measurement } & \multirow{3}{*}{$\begin{array}{l}\text { Blasting media } \\
\Delta 15 \text { to } 35 \mu \mathrm{m} \\
50 \text { to } 70 \mu \mathrm{m}\end{array}$} & \multicolumn{2}{|c|}{ 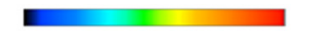 } \\
\hline $\mathrm{n}_{\text {Surfaces }}$ & 2 & $\lambda_{\mathrm{s}}$ & $2.5 \mu \mathrm{m}$ & Lens & $\mathrm{x} 20$ & & $0 \mu \mathrm{m}$ & $-7 \mu \mathrm{m}$ \\
\hline $\mathrm{n}_{\text {Measurements }}$ & 5 & $\lambda_{\mathrm{c}}$ & $0.8 \mathrm{~mm}$ & & & & & $250 \mu \mathrm{m}$ \\
\hline
\end{tabular}

Fig 11. a) Roughness and b) topography images of tool surfaces.

rectangular functional element is only reduced by $0.20 \%$. Additionally, an increase of the friction of the die as simulated in the global model for example by abrasive blasting of the tool surface would probably reduce tool life by producing surfaces defects. These surfaces defects can initiate cracks and therefore reduce fatigue strength [14]. Hence, the friction has to be adapted locally on all tool surfaces except for the die.

\section{Tailored surfaces}

The numerical study has shown that tailored surfaces can be used to improve SBMF processes. The surface modifications should increase friction to reduce the material flow in areas with low tribological loads. Further requirements are a local applicability as well as an efficient production of the tailored surfaces. Consequently, abrasive blasting has potential as a surface modification because it can be applied locally and is a cost efficient technique to influence the surfaces integrity of tools [15]. Abrasive blasting roughens the surfaces. Hence, the aim of the experiments is to investigate the potential of tool-sided abrasive blasting as a surface modification to increase friction.

For the blasting of the tool surfaces, two different blasting media with a particle size between 15 and $35 \mu \mathrm{m}$ and a hardness of $3000 \mathrm{HV}$ as well as 50 to $70 \mu \mathrm{m}$ and $2400 \mathrm{HV}$ were used. The material of both blasting media is $\mathrm{Al}_{2} \mathrm{O}_{3}$. The particles are angular to roughen the surfaces. The pressure of the blasting process is varied from 0.1 to $0.3 \mathrm{MPa}$ in three steps. Lower pressures are impeded by the blasting process. Higher pressures would destroy the blasting particles. The ground tool surfaces are blasted for $47 \mathrm{~s}$ with a distance of $40 \mathrm{~mm}$ to create uniform surface properties. The blasting time was investigated in preliminary tests to create a surface with homogenous properties. A $90^{\circ}$ angle between nozzle and surfaces was chosen, since this angle causes the highest roughening of the surfaces [16].

\subsection{Analysis of blasted tool surfaces before RCT}

The ground tool surfaces have a reduced peak height $R p k$ of $0.20 \pm 0.01 \mu \mathrm{m}$ before blasting. The abrasive blasted tool surfaces are compared to lapped surfaces in Figure 11a as a reference since lapping is a widespread surface finishing for forming tools.

The lapped surfaces have a reduced peak height of $0.09 \pm 0.01 \mu \mathrm{m}$. The roughness of all blasted surfaces is higher than the roughness of lapped or ground surfaces. The lowest roughness of $0.33 \pm 0.06 \mu \mathrm{m}$ compared to other blasted surfaces is achieved with the fine blasting media and the lowest pressure of $0.1 \mathrm{MPa}$. Blasting media with a greater particle size and a blasting pressure of $0.3 \mathrm{MPa}$ causes the roughest surface with a mean roughness of $0.89 \pm 0.0 .31 \mu \mathrm{m}$. Both, the particle size and the blasting pressure positively influence the roughness of the surface, since they increase the kinetic energy of the particles ablating the surface. These effects can also be seen in [17]. The high standard variation of the roughness of the blasted surfaces can be explained by the particle sizes varying between 15 and $35 \mu \mathrm{m}$ as well as between 50 and $70 \mu \mathrm{m}$. The results demonstrate that abrasive blasting can be used to increase the roughness of tool surfaces.

As shown in Figure 11b, the blasting process changes the topography of the tools. The topography before the blasting is characterised by orientated grinding marks. Lapped surfaces are smooth and have no preferential direction. The blasting process creates a topography with stochastically dispersed peaks. This topography is created by a combination of platelet formation and micromachining by the blasting media [18]. After blasting with low pressure and fine particles, the surfaces is characterised by small peaks. Grinding marks are partially still visible. The highest blasting pressure in combination with the greatest particle size causes a topography with greater peaks. The grinding marks are no longer apparent, since they were removed by a blasting process with a higher 
a)

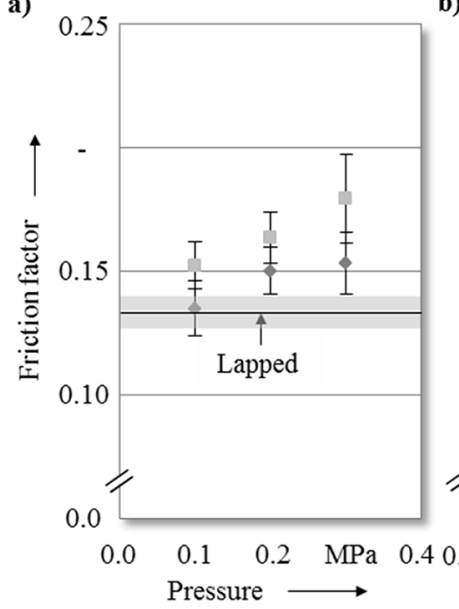

b)

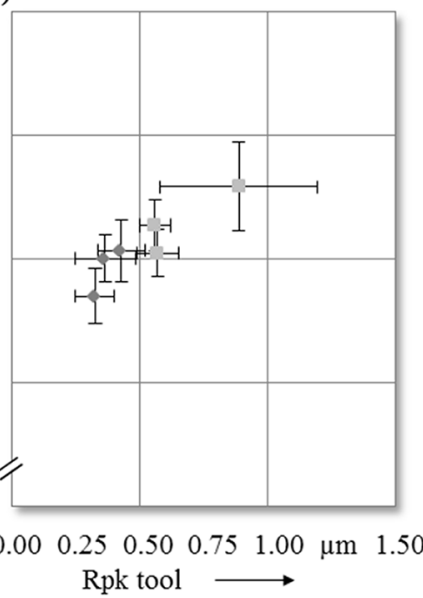

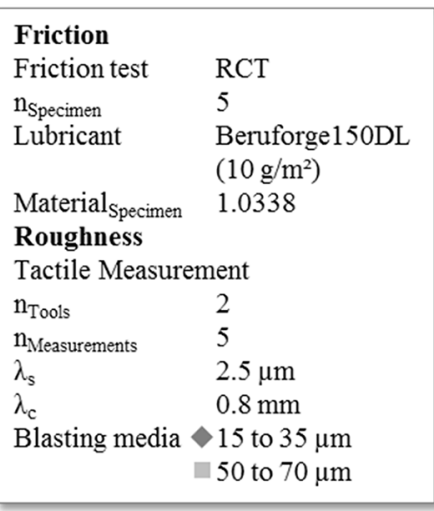

Friction

Beruforge150DL

$\left(10 \mathrm{~g} / \mathrm{m}^{2}\right)$

Material $_{\text {Specimen }} 1.0338$

$2.5 \mu \mathrm{m}$

$\lambda_{\mathrm{c}}$ Blasting media 15 to $35 \mu \mathrm{m}$

50 to $70 \mu \mathrm{m}$

Fig. 12. a) Influence of blasted tool topography on the friction factor and b) relation between tool roughness and friction factor.

ablation rate due to higher blasting pressure and particle size. A homogeneous surface is created. The same effect of the removal of orientated grinding marks by shot peening of tool surfaces can be seen in [19].

\subsection{Functional relation between tool surface topography and friction}

The RCT is used to analyse the influence of the tool surface on the friction. As a reference, lapped tools are utilized. Lapped tool surfaces cause a friction factor of $0.133 \pm 0.007$. As shown in Figure 12a, the friction factors of all abrasive blasted surfaces are higher. Hence, abrasive blasting of tool surfaces increases the friction. The highest friction factor of $0.179 \pm 0.018$ occurs for tools which are blasted with $0.3 \mathrm{MPa}$ pressure and a particle size between 50 and $70 \mu \mathrm{m}$. As shown in Figure 12a, an increase in blasting pressure and particle size both cause higher friction.

Since both varied blasting parameter positively influence the tool roughness, the functional relation between tool roughness and friction is analysed in Figure 12b. A higher reduced peak height of the tool surfaces causes higher friction. The positive functional relation between the roughness and the friction is caused by the mechanical interlocking of tool- and workpiece-sided roughness peaks.

\subsection{Analysis of blasted tool surfaces after RCT}

Forming tools have to withstand a great number of strokes. Due to the tool-sided application of tailored surfaces, their functional stability is of great importance for an efficient usage. For this reason, the changes of a selected blasted tool surface in terms of tool topography and tribological behavior was investigated for a greater number of forming operations. In Section 3, a high increase in friction was defined as a requirement for tool-sided surface modifications. A surface blasted with $0.3 \mathrm{MPa}$ pressure and a grain size of 50 to $70 \mu \mathrm{m}$ was chosen for the following investigations, since this surface modification caused the highest friction factor in Section 4.2. For this examination, 100
RCT are conducted and the roughness of the tools is characterized after every fifth respectively after every tenth forming operations starting form stroke 50 . The change in tool roughness due to the forming process is illustrated in Figure 13a. After five forming operations, the initial reduced peak height of the tools has decreased by $45 \%$ from $0.89 \pm 0.31 \mu \mathrm{m}$ to $0.49 \pm 0.06 \mu \mathrm{m}$. Subsequently, no change in roughness is detectable for the next 95 forming operations. In addition to the change in tool roughness, the friction factors of the $100 \mathrm{RCT}$ specimens were determined to investigate the functional stability of the tailored tool surface (Fig. 13b). The average friction factor is $0.199 \pm 0.014$. No trend of a change in friction is detected. For forming operations 6 to 100, the stable friction is explained by the constant tool roughness. Because there is no substantive change in friction for the first to fifth forming operation, but a decrease in tool roughness of $45 \%$, one can assume that the roughness peaks of the blasted tools are smoothed by the tribological loads of the first stroke. Since the load carrying capacity of a smoothed surface is increased [20], the strength of the smoothed roughness peaks might be great enough to withstand the tribological loads of the following 99 forming operations without changing the tool roughness. Consequently, there is no significant change in friction for the following forming operations as can be seen in Figure 13b. A similar behavior - that under high tribological loads the initial surface is changed in the beginning of contact and the subsequent tribological behavior is defined by the changed surfacewas also reported in [21]. Summarizing it was shown, that the friction increasing function of the blasted surfaces is stable for the first 100 forming operations.

\section{Conclusions and outlook}

The numerical investigations have shown that SBMF processes are characterised by areas with widely varying tribological loads. High tribological loads which are characteristic for bulk forming operations are caused by the forming of functional elements. The material flows in 

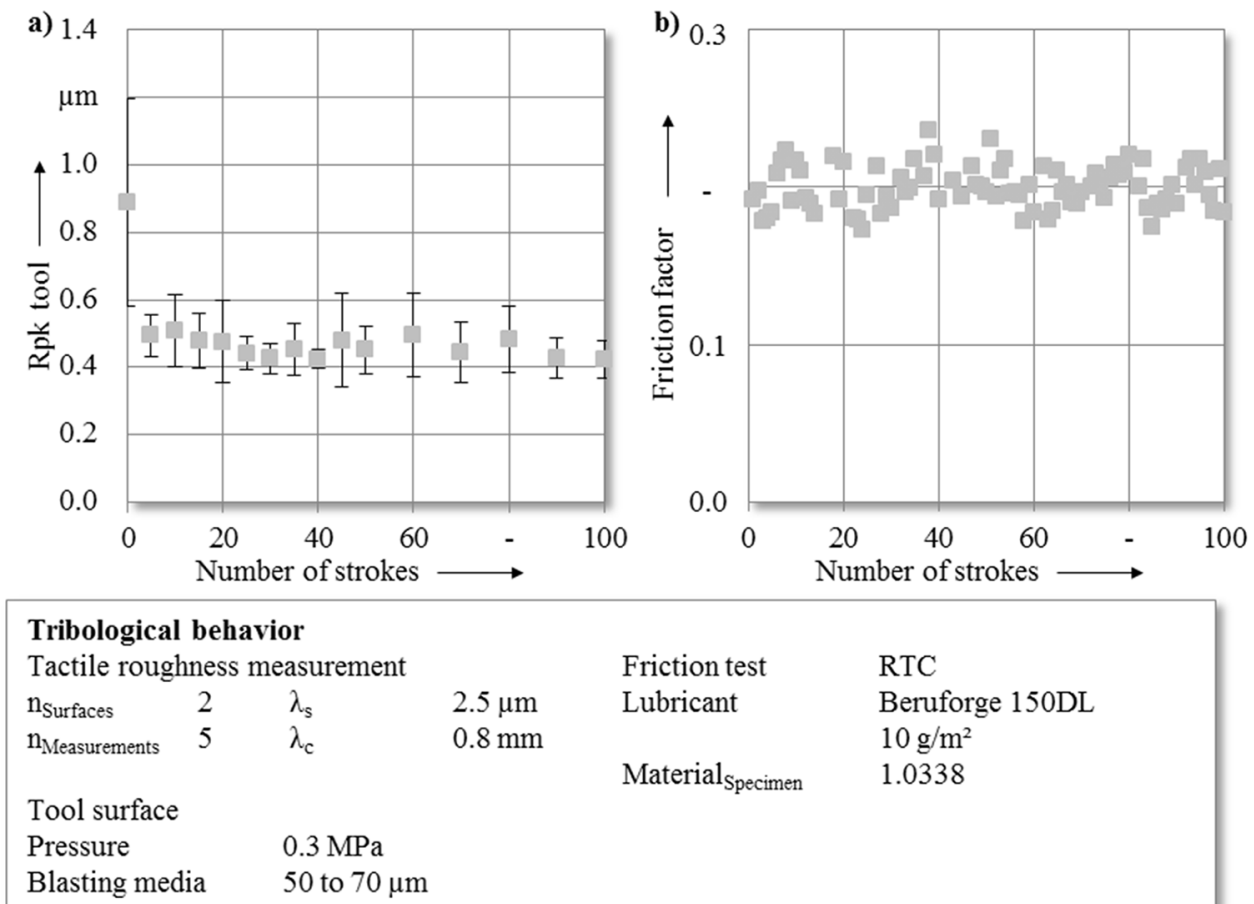

Fig. 13. a) Roughness and b) topography images of tool surfaces before and after RCT.

adjacently areas with lower tribological loads. Hence, the die filling and as a consequence the quality of the produced part in terms of geometrical accuracy are reduced.

It is shown that a local increase of the friction in areas with lower tribological loads controls the material flow and increases the quality of the produced parts by inhibiting the material flow away from the functional elements and enhancing the material flow into the die cavities. In addition, a locally adapted tribological system reduces the increase of forming forces due to higher friction compared to a globally adapted tribological system. Hence, surface modifications for a local increase of friction need to be developed.

The potential of abrasive blasting of tool surfaces was analysed in RCT. Abrasive blasting of ground tool surfaces increases the roughness. Higher surfaces roughness due to abrasive blasting increase the friction by mechanical interlocking of tool- and workpiece-sided roughness peaks. Both, the blasting pressure and the particle size of the blasting media positively influence the friction since both increase the roughness and the size of the roughness peaks. Abrasive blasting of tool surfaces is suitable to locally increase the friction in SBMF processes.

In addition to the friction-enhancing function of blasted surfaces, the functional stability of the modifications is of great importance due to the tool-sided application. The investigation on a selected blasted surface in the RCT shows that this surface has a constant tribological behavior for 100 forming operations. In order to investigate the wear behavior for an industrial relevant number of forming operations, the tailored surfaces have to be characterized in future investigations on an automated wear test rig.
This work was supported by the German Research Foundation within the scope of the Transregional Collaborative Research Centre on sheet-bulk metal forming (CRC/TR 73, Subproject A2 and $\mathrm{C} 1$ ).

\section{References}

1. K. Lange, Handbook of metal forming, 1st edn., McGrawHill, New York, 1985

2. M. Merklein, J. Allwood, B.-A. Behrens, A. Brosius, H. Hagenah, K. Kuzman, K. Mori, A.E. Tekkaya, A. Weckenmann, CIRP ANN.-Manuf. Techn. 61 (2012) 725-745

3. International cold forging group, Tool life and tool quality in cold forging, Meisenbach Verlag, Bamberg, 2002

4. M. Löffler, R. Schulte, D. Freiburg, D. Biermann, D. Stangier, W. Tillmann, M. Merklein, Int. J. Mater. Form. 12 (2019) 17-26

5. L. Kirkhorn, V. Bushlya, M. Andersson, J.E. Stahl, Wear 302 (2013) 1268-1278

6. K. Lange, A. Hettig, M. Knoerr, J. Mater. Process. Tech. 35 (1992) 495-513

7. D. Gröbel, J. Koch, U. Vierzigmann, U. Engel, M. Merklein, Procedia Eng. 81 (2014) 401-406

8. F. Klocke, Manufacturing processes: Forming, 1st edn., Springer-Verlag, Berlin, 2013

9. U. Vierzigmann, Ph.D. thesis, Friedrich-Alexander-University Erlangen-Nürnberg, 2016

10. DIN-Normenausschuss Technische Grundlagen, in DIN EN ISO 1356-2, edited by Deutsches Institut für Normung e. V, Beuth Verlag, Berlin, 1998

11. P. Groche, C. Müller, J. Stahlmann, S. Zang, Tribol. Int. 62 (2013) 223-231

12. N. Bay, A. Azushima, P. Groche, I. Ishibashi, M. Merklein, M. Morishita, T. Nakamura, S. Schmid, M. Yoshida, CIRP ANN.-Manuf. Tech. 59 (2010) 760-780 
13. U. Engel, Habilitation thesis, Friedrich-Alexander-University Erlangen-Nürnberg, 1996

14. Y. Murakami, Int. J. Fatigue 41 (2012) 2-10

15. K. Chander, Mater. Des. 30 (2009) 2895-2902

16. J. Wigren, Surf. Coat. Technol. 34 (1988) 101-108

17. M. Mellali, A. Grimaud, A.C. Leger, P. Fauchais, J. Lu, J. Therm. Spray Technol. 6 (1997) 217-227
18. A.W. Momber, Y.C. Wong, R. Ij, E. Budidharma, Tribol. Int. 34 (2002) 271-281

19. M. Babic, S. Mitrovic, D. Adamovic, D. Dzunic, F. Zivic, in: J. Champaigne (Ed.), Proceedings of the 11th International Conference on Shot Peening, South Bend 2011, pp. 12-15

20. A. Rosenkranz, Ph.D. thesis, University Saarland, 2014

21. P.J. Blau, Wear 71 (1981) 29-43

Cite this article as: Marion Merklein, Maria Löffler, Daniel Gröbel, Johannes Henneberg, Investigation on blasted tool surfaces as a measure for material flow control in sheet-bulk metal forming, Manufacturing Rev. 6, 10 (2019) 